\title{
Prolonged occupational standing: the impact of time and footwear
}

\author{
Jennifer Anderson, Christopher J. Nester, Anita E. Williams \\ School of Health Sciences, University of Salford, Salford, United Kingdom
}

\begin{abstract}
Prolonged occupational standing is strongly related to musculoskeletal disorders. Despite being the main external load bearing interface between the floor and musculoskeletal system, and easy to manipulate, footwear is often ignored as an intervention for standing related disorders. This study aimed to record the effect of prolonged standing on the body and determine the impact of footwear material. Two pairs of surgical clogs were tested, varying only in material hardness. Participants $(n=12)$ undertook 3 hours of standing in each shoe whilst they completed a repetitive series of simulated work tasks. Biomechanical and subjective data were recorded at the start, end and every 30 minutes during the three hours of standing. There was an increase in discomfort of the low back and all lower extremity regions alongside an increase in calf circumference, selected kinematic and kinetic variables, and changes in plantar pressure distribution over the three hours. Altering the footwear material impacted on low back discomfort and plantar pressures. Shoe preference varied amongst individuals, but was consistently associated with an increased medial midfoot contact area. Overall, this study has demonstrated the effect of prolonged standing on the body, has shown footwear impacts both subjective and biomechanical measures and provides information regarding individual differences and footwear preferences.
\end{abstract}

Keywords: musculoskeletal disorders; shoes; discomfort; footwear hardness; plantar pressure; EMG; footwear preference

The Version of Record of this manuscript has been published and is available in Footwear Science published 26 Nov 2018 available:

https://www.tandfonline.com/doi/abs/10.1080/19424280.2018.1538262 


\section{Introduction}

Prolonged standing is necessary in various occupations including health care, food service, factory and retail environments (Waters and Dick, 2015; Anderson, Williams \&Nester, 2016). There is a 1.48-1.9fold increased risk of low back pain and 1.7 fold increase in risk of lower extremity or foot pain when standing for prolonged periods (Andersen, Haahr \& Frost, 2007; Tissot, Messing, \& Stock, 2009; Sterud \& Tynes, 2013). Prolonged occupational standing is also linked to chronic disease such as joint degeneration and venous conditions (Meijsen \& Knibbe, 2007; Bergan et al., 2006; Halim \& Omar, 2011; Sulsky et al., 2012). Musculoskeletal disorders reduce worker productivity (Halim \& Omar, 2011) and have financial consequences (O’Neill, 2005) as well as impacting life outside of work. Identifying work place interventions that reduce the impact of prolonged standing on health is therefore imperative.

Acute periods of standing (30 minutes-4 hours) also have detrimental impacts on the body. Discomfort measures of the feet, lower limb and lower back as well as feelings of fatigue are consistently shown to increase with time (King, 2002; Antle, Vezina, Messing, \& Côté, 2013; Orlando and King, 2004; Coenen et al. 2017; Zander, King, \& Ezenwa, 2004). A systematic review identified blood pooling, measured through blood flow, skin temperature and leg circumference/volume, was frequently reported to increase with time standing (Coenen et al., 2017), with strong correlations to discomfort in the measured regions (Antle et al., 2013). The combination of gravity and the lack of muscle contraction contribute to an increased venous pressure, venous stasis and an increased foot/calf volume (Tüchsen, Hannerz, Burr \& Krause, 2005), which is thought to cause a build-up of paininducing metabolites and place stress on passive structures (Coenen et al., 2017; Edwards, 1988). Although muscular factors are thought to impact discomfort, results from studies assessing lower limb fatigue using electromyography (EMG) are inconsistent (Antle et al., 2013; Coenen et al., 2017; Gregory \& Callaghan, 2008; Brownie \& Martin, 2015; Garcia, Laubli, \& Martin, 2015). There is some evidence to suggest a role of co-contraction of bilateral lower back muscles in the development of lower back pain (Nelson-Wong, Gregory, Winter, \& Callaghan, 2008; Nelson-Wong \& Callaghan, 2010) but this is still limited (Coenen et al., 2017).

Softer or anti fatigue floorings in the work place are consistently reported to reduce discomfort of the lower back and lower extremities when standing, although floors that are too soft fail to reduce discomfort (Cham \& Redfern, 2001; King, 2002; Lin, Chen, \& Cho, 2012; Orlando \& King, 2004; Waters \& Dick, 2015). Cham and Redfern (2001) reported greater elasticity and stiffness and decreased energy absorption as preferred flooring characteristics. Softer flooring is associated with increased postural sway, which is thought to increase the venous muscle pump action and reduce blood pooling (Kim \& Stuart-Buttle, 1994). However, investigation of blood pooling when standing on softer floors has indicated both a decrease (Lin et al., 2012; Madelaine, Voigt, \& Arendt-Nielsen, 1998) and 
no effect on blood pooling (Cham \& Redfern, 2001; Zander et al., 2004). The literature does not generally support any effect of soft flooring or footwear on muscle activity during standing (Aghazadeh et al., 2015; Cook, Branch, Baranowski, \& Hutton, 1993; Hansen, Winkel, \& Jorgensen, 1998).

A limitation of these flooring studies is that the footwear used is largely overlooked, despite the obvious impact on the interaction between the floor and musculoskeletal system (Goonetilleke, 1999). Furthermore, footwear has been widely ignored as an intervention for problems associated with prolonged standing, despite the advantage of being person specific and portable. As with flooring, softer materials for soles and insoles have been associated with reduced discomfort in the lower back, legs and feet when standing (Hansen et al., 1998; King, 2002; Orlando \& King, 2004). However, these studies do not isolate specific footwear characteristics as responsible for any effects on standing. They include, comparisons of barefoot and shod standing (Lin et al., 2012) and a hard clog compared to a sports shoe (Hansen et al., 1998), which vary geometrically as well as in material characteristics. Studies investigating insoles did not control for shoe type (Orlando \& King, 2004). A further criticism is that studies do not always report data throughout the period of prolonged standing and hence it is not possible to understand the rate of change in biomechanical or physiological variables. Finally, plantar pressure was not considered in these studies, despite its relationship to both footwear characteristics and discomfort (Wiggerman \& Keyserling, 2015).

The impact of footwear characteristics on prolonged standing requires further research with a focus on isolated footwear characteristics such that interventions might be optimised. Therefore, this study aimed to explore the effects of prolonged standing and the impact of altering footwear material hardness over three hours on plantar pressure, blood pooling, muscle activity, kinetics, kinematics and subjective discomfort.

\section{Method}

\section{Participants}

Twelve healthy participants were recruited from a University population with UK foot size 5, 6,8 or 9 as the test footwear was only available in these sizes (male: 5 , female: 7 , age: $28 \pm 5$ years; weight: $68 \pm 11 \mathrm{~kg}$; height: $1.7 \pm 0.1 \mathrm{~m}$; UK shoe sizes: average female; $6.0 \pm 1.1$; average male: $7.8 \pm 1.0$ ). Ethical approval and individual consent were gained prior to testing. The population size is reflective of previous prolonged standing studies of similar length ( $\mathrm{n}=8-11$, Cham and Redfern, 2001, Orlando and King, 2004; Hansen et al., 1998; Antle et al., 2013).

\section{Footwear}

The shoes were surgical clogs made of Ethylene-vinyl acetate (EVA) (EziKlog, Toffeln Ltd, UK), from the same tools (14mm pitch, 30mm heel height and a slight arch support) but using two material variations (Figure 1). Footwear was mechanically characterised in terms of hardness, density, 
energy absorption and shock absorption according to ISO standards (INESCOP, Spain). The materials varied by $11 \%$ in Shore A hardness, with the softer shoe at $34^{\circ}$ and the harder shoe at $38^{\circ}$ (Table 1 ). The shoes will be referred to as 'softer shoe' and 'harder shoe' (harder shoe has the comparatively greater Shore A, density, energy absorption, deceleration and a reduced penetration and energy return). The average weight across sizes was $210 \mathrm{~g} /$ shoe.

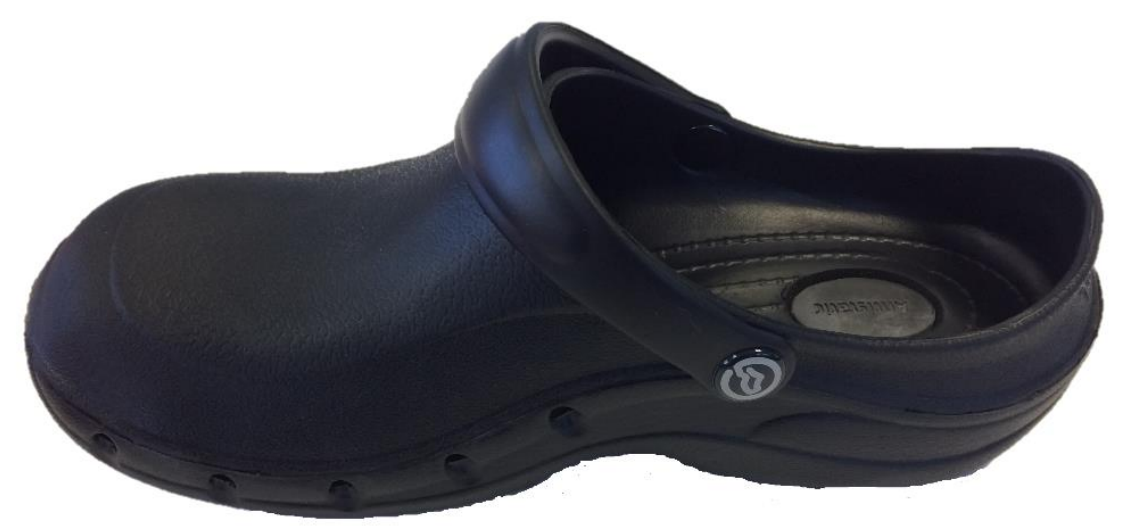

Figure 1: EVA shoe used for testing (Eziklog, Toffeln Ltd, UK). Both shoes had identical geometry but were made in material that the manufacturers deemed different in manual feel.

\section{Data Collection}

Discomfort measures for the whole body, low back, upper leg, knee, calf, ankle and foot were measured using a 100mm visual analogue scale (VAS), ranging from 'no discomfort' to 'worst discomfort imaginable', as previous (Nelson, Howarth \& Callaghan, 2010). Whole body tiredness and shoe sole hardness were measured on a $100 \mathrm{~mm}$ VAS (ranging from 'not tired at all' to 'very tired', and 'extremely soft' to 'extremely hard').

Table 1 - External testing results of mechanical properties of tested footwear (INESCOP, Spain).

\begin{tabular}{|c|c|c|c|c|}
\hline \multicolumn{2}{|c|}{ Criteria } & Softer shoe & Harder shoe & \% difference \\
\hline \multicolumn{2}{|c|}{ Hardness (cellular - Shore A $\left(^{\circ}\right)$ ) } & 34 & 38 & $11 \%$ \\
\hline \multicolumn{2}{|c|}{ Hardness (compact - Shore A/3s) } & 69 & 76 & $10 \%$ \\
\hline \multicolumn{2}{|c|}{ Density (cellular $\mathbf{g} / \mathrm{cm}^{3}$ ) } & 0.20 & 0.22 & $10 \%$ \\
\hline \multicolumn{2}{|c|}{ Energy Absorption (J) } & 31.2 & 34.2 & $10 \%$ \\
\hline \multirow{3}{*}{$\begin{array}{c}\text { Shock } \\
\text { absorption }\end{array}$} & Deceleration $\left(\mathrm{m} / \mathrm{s}^{2}\right)$ & 100 & 120 & $20 \%$ \\
\hline & Penetration (mm) & 8.0 & 6.5 & $18 \%$ \\
\hline & \% energy return & 32 & 29 & $9 \%$ \\
\hline
\end{tabular}


Calf circumference was measured at the midpoint between the fibula head and lateral malleolus, (marked onto the leg) using a Gulick II tape measure (Country Technology Inc., Gays Mills, WI) which enabled a constant tension to be applied.

Surface electromyography (EMG) was collected bilaterally (Noraxon, DTS, Noraxon Inc., Scottsdale, AZ) at $1500 \mathrm{~Hz}$. from the tibialis anterior (TA), medial gastrocnemius (MG) and lumbar erector spinae (ES). A pair of $\mathrm{Ag} / \mathrm{AgCl}$ electrodes (Noraxon) were attached to prepared skin (shaved, abraded and alcohol wiped) over the belly of each muscle, following the SENIAM guidelines combined with visual muscle identification. Bilateral ES maximal contractions were taken as follows. Participants lay prone on a plinth and padded straps around the upper thigh and shoulders stabilised the participant whilst they tried to bring their upper and lower bodies together. Verbal encouragement was given to ensure maximal contractions were reached.

Kinetic data was collected on two adjacent 400*600 mm Kistler force plates (9286AA, Kistler Instruments Ltd. Winterhur, Switzerland) at $1500 \mathrm{~Hz}$. Kinematic data was collected at $100 \mathrm{~Hz}$ using a 10 camera Vicon system (MX-T40-S, Vicon Motion Analysis Inc., Oxford, UK). Reflective markers were placed on the anterior and posterior superior iliac spine, greater trochanter, medial and lateral knee, medial and lateral ankles. Four markers were placed on the shoe (toe, heel, medial and lateral) and clusters of 4 markers on the thigh and shanks. A small portion of the lateral heel lip of the shoe was removed to allow a cluster of three markers to be attached to the lateral calcaneus and to ensure this cluster did not catch the shoe.

A Pedar insole (Novel $\mathrm{GmbH}$, Germany, $50 \mathrm{~Hz}$ ) was used to measure plantar pressure between the foot and the shoe. The insole is $2 \mathrm{~mm}$ thick, contains 99 capacitive sensors and has been shown to more accurate and repeatable than other in-shoe pressure measuring insoles (Price, Parker, $\&$ Nester, 2016). The large number of cells enables the insole to be divided into custom regions. Due to the wide fit of the shoe, the Pedar insole was placed inside a thin sock to ensure minimal movement between the foot and Pedar insole.

\section{Protocol}

Participants attended two sessions, at least 24 hours apart, both starting at the same time of day. One session was used to test the hard shoe, and the other to test the soft shoe. The testing order was randomised with the same protocol followed for each session.

Instructions were given to stand with one foot on each force plate. A thin vertical sheet of plastic between the two force platforms ensured the two feet could not cross over. Participants stood and completed tasks on a $0.9 \mathrm{~m}$ high work top, with task instructions projected onto the wall facing the participant. The tasks simulated a range of work like movements and included cognition, auditory response, manual dexterity and object moving (Appendix 1). A sequence of tasks lasted 30 minutes, 
controlled using timing of instructions (PowerPoint slides) but varied slightly in each 30 minute period to minimise boredom. Participants could not move away from the work bench but could move as they liked at the bench to complete the tasks. The position of the work bench and the tasks ensured the participants feet remained on the separate force platforms and no walking was required.

Biomechanical data was collected over two tasks. The first, "static task" involved screwing nuts onto bolts through a stand directly in front of the participant (see appendix 1 - 'nuts and bolts'), which forced the participant to keep their feet still on the floor. The second task was more dynamic (see appendix 1 - 'ladder task') and involved moving objects around the perimeter of the work table (table size: $1.5 \times 0.9 \mathrm{~m}$ ) based on auditory cues and therefore required the participant to shift their weight from left to right (no stepping was required).

All measures (calf circumference, VAS scores and kinematic, kinetic, plantar pressure and EMG measures for both tasks) were recorded 7 times: at the start and end of the 3 hours and every 30 minutes in-between. Calf circumference was measured three times at each time point and the mean calculated. Participants did not stop for biomechanical data collection but were asked to perform a heel raise (the heel leaves the floor) to allow synchronisation of the Pedar data and data collected through Vicon Nexus. Recording VAS scores was a task given to participants whilst calf circumference was taken simultaneously and participants remained standing throughout.

Once the trials had been completed for both shoes, participants were asked which shoe they preferred.

\section{Data Analysis}

Kinematic data was imported into Visual 3D (v6, C-Motion, Inc., Germantown, MD, USA), and filtered (low-pass Butterworth 8Hz). Pelvis and bilateral thigh, shank and foot segments were used to calculate joint angles with Cardan sequence ( $x$ (sagittal) $-y($ frontal)- $z$ (transverse)). To define the foot motion, the lateral and medial malleoli and metatarsal markers were projected onto the floor to create the proximal and distal locations of the segment and movement of the segment was tracked using the heel cluster relative to the shank. Kinetic data was filtered (low-pass Butterworth $10 \mathrm{~Hz}$ ) and internal moments calculated for the ankle, knee and hip (normalised to body weight). At each of the 7 measurement intervals, the data was cropped to 1 minute, starting when the heel marker on the shoe returned to its original position in the vertical axis after the heel raise task and therefore standing had recommenced. A mean value for the angles and moments was derived for each minute of data. Mean centre of pressure position during the 1 minute, normalised to foot length, was also exported.

In-shoe pressure data was analysed in MATLAB (R2016b). Data was cropped to start when the heel raise ended (i.e. after the heel pressure values dropped and returned to the mean value), to ensure the timing was the same as the kinematic/kinetic data. This was based on visual selection from a 
pressure graph. As it has been suggested that the drift that occurs in the Pedar insoles over time should be adjusted for on a trial by trial basis (Arndt, 2003), the mean heel pressure recorded during the heel raise (i.e. when no pressure was applied) was subtracted from all data in the corresponding minute. The following regions were included: whole foot, heel, medial midfoot, lateral midfoot, Metatarsophalangeal Joint (MTPJ) 1, MTPJ 2-3, MTPJ4-5, hallux, and toe areas (Figure 2). Mean and peak pressures were extracted from each region for the 1 minute epoch. Mean contact area for each region was calculated as the percentage of the area $\left(\mathrm{cm}^{2}\right)$ that was registering pressure $>5 \mathrm{KPa}$ compared to the entire area of the section. The mean pressure time integral (PTI) was calculated for each region over the entire minute.

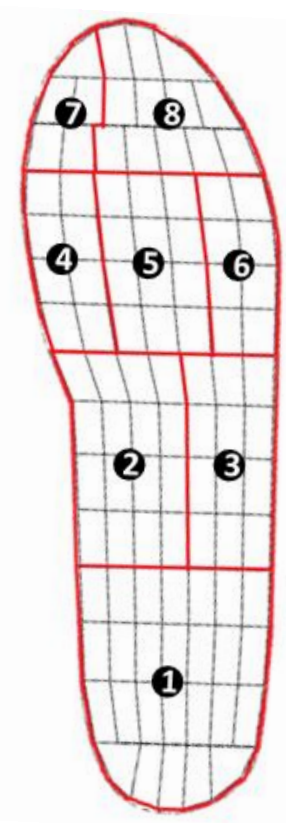

Figure 2. In-shoe pressure analysis break down of areas where each square represents the area covered by an individual sensor. 1 = heel; 2 = medial midfoot; 3 = lateral midfoot; 4 = MTPJ1; 5 = MTPJ2-3; 6 = MTPJ4-5; 7 $=$ hallux; $8=$ toes.

EMG was analysed using MATLAB. Data was filtered (Butterworth bandpass filter 50-400Hz) and rectified. Changes in the EMG signals over the 3 hours were assessed in both the time domain (root mean square) and power domain (median frequency). Root mean square (RMS) was calculated for each 1 second non-overlapping window over 60 seconds. The overall value was taken as the average of the 60 data points for each muscle. The median frequency (MDF) was calculated over the 60 seconds of data. For both the RMS and MDF values over time, regression analysis (first order polynomial) was performed and the slope gradient was used to determine the direction and rate of change over time (if any).

A linear envelope was applied (Low pass Butterworth $2.5 \mathrm{~Hz}$ ) to the ES EMG data and was normalised to the maximum value recorded in the maximal contraction test. The co-activation 
coefficient and cross-correlation values were used to assess for co-activation between the bilateral ES muscles, as previously defined (Nelson-Wong \& Callaghan, 2010).

All data was considered in absolute values (e.g. $\mathrm{kPa}$ ) and also the change from the start of the 3-hour session. Looking at the change from start removes any effect of the individual starting data values as a bias and focus' on the impact of time.

Statistical tests were conducted using SPSS v23 (IBM). Two-way within subject ANOVA with (1) footwear (harder and softer) and (2) time (0,30,60, 90, 120, 150, 180 minutes) as the within subject factors. Preferred vs less preferred footwear were assessed in the same way. Where a main effect was found, a Bonferroni post-hoc was used to determine where the differences lay. Independent t-tests were used to test differences between individuals that preferred the harder shoe vs those that preferred the softer shoe. For all statistical tests including post hoc results, the alpha value was set at 0.05 .

\section{Results}

\section{The effect of time}

\section{Discomfort and leg circumference}

All discomfort variables, as measured through the VAS, showed a significant main effect of time $\mathrm{p}<0.05$ (Table 2). Post hoc tests found every variable increased significantly within 90 minutes. Foot discomfort increased to a greater extent than any other variable (average change from start to end $=41.7 \pm 16.2 \mathrm{~mm}$ ), with a significant increase within 30 minutes. Other variables showed a maximum increase of between 18.3-28.1 mm.

Leg circumference increased over time $\left(\mathrm{F}_{6,66}=55.74, \mathrm{p}<0.001\right)$. By the end of the 3 hours, this had increased by an average of $0.6 \pm 0.2 \mathrm{~cm}$. The post hoc showed significant increases $(p<0.05)$ between baseline and 60 minutes, at 90 minutes and at 180 minutes.

\section{Dynamic task}

Whole foot mean pressure and contact area increased within 60 minutes (Table 3). The main changes were seen in the heel and midfoot regions. In the heel, values started at $26.61 \mathrm{kPa}$ (mean pressure), $24.7 \%$ (contact area) and $1571.43 \mathrm{kPa} \mathrm{s}$ (PTI), and after 3 hours these had increased 53\%, $72 \%$ and 55\% respectively. Lateral midfoot changes became significant after 60 minutes, with average maximum changes of $40 \%$ (mean pressure), 35\% (contact area) and 54\% (PTI). Midfoot changes occurred between 60 and 150 minutes with increases from baseline of 78\% (mean pressure), 14\% (peak pressure), $72 \%$ (contact area) and 108\% (PTI). Increased contact area were also recorded in all MTPJ and toes regions. 
Table 2: Change in subjective variables over time. Arrows indicate change from start, or previous increases. To calculate the average maximum change, the average of each individuals change was taken.

\begin{tabular}{|c|c|c|c|c|c|c|c|c|c|c|}
\hline \multirow[t]{2}{*}{ Measure } & \multicolumn{6}{|c|}{ Time(minutes) } & \multicolumn{2}{|c|}{$\begin{array}{l}\text { Average max change } \\
\text { from start (mm) }\end{array}$} & \multirow[t]{2}{*}{ F value } & \multirow{2}{*}{$\begin{array}{c}P \\
\text { value }\end{array}$} \\
\hline & 30 & 60 & 90 & 120 & 150 & 180 & Mean & $\mathrm{SD}$ & & \\
\hline Whole body discomfort & $\uparrow$ & & $\uparrow$ & $\uparrow$ & & $\uparrow$ & 24.2 & 16.5 & 16.94 & $<0.001$ \\
\hline Whole body fatigue & & & $\uparrow$ & & $\uparrow$ & $\uparrow$ & 23.7 & 16.7 & 17.63 & $<0.001$ \\
\hline Shoe sole hardness & & & $\uparrow$ & & $\uparrow$ & & 26.2 & 14.8 & 26.06 & $<0.001$ \\
\hline Low back discomfort & & $\uparrow$ & & & $\uparrow$ & & 21.0 & 15.3 & 22.28 & $<0.001$ \\
\hline Upper leg discomfort & & & $\uparrow$ & & & & 18.3 & 11.6 & 18.27 & $<0.001$ \\
\hline Knee discomfort & & & $\uparrow$ & & & $\uparrow$ & 28.1 & 17.3 & 21.34 & $<0.001$ \\
\hline Calf discomfort & & & $\uparrow$ & & $\uparrow$ & & 24.8 & 17.6 & 18.48 & $<0.001$ \\
\hline Ankle discomfort & & $\uparrow$ & & & & & 26.7 & 20.0 & 16.99 & 0.001 \\
\hline Foot discomfort & $\uparrow$ & & $\uparrow$ & & $\uparrow$ & $\uparrow$ & 41.7 & 16.2 & 67.65 & $<0.001$ \\
\hline
\end{tabular}

Ankle dorsiflexion increased over time $\left(\mathrm{F}_{6,66}=5.60, \mathrm{p}=0.004\right)$ although there were no significant post hoc results. The COP shifted laterally over time $\left(\mathrm{F}_{6,66}=5.58, \mathrm{p}=0.008\right)$. There was an increase in the internal ankle inversion moment by an average $28 \%\left(0.027 \mathrm{Nm} / \mathrm{kg} ; \mathrm{F}_{6,66}=9.45, \mathrm{p}=0.001\right)$ with the increase significant from 90 minutes. The knee became more flexed over time $\left(F_{6,66}=3.029, p=0.038\right)$, with a significant increase at 150 minutes (average maximum change $=2.4 \pm 2.3^{\circ}$ ). No changes in $\mathrm{EMG}$ variables were recorded over time.

\section{Static task}

Plantar pressure during the static task changed for the whole foot and heel region, with significant increases occurring within 30 minutes (Table 3). Mean heel pressure increased 18\%, peak pressure 54\%, contact area $35 \%$ and PTI $87 \%$.

Ankle inversion moment had increased by an average of $40 \%\left(0.03 \mathrm{Nm} / \mathrm{kg} ; \mathrm{F}_{6,66}=13.21\right.$, $\mathrm{p}<0.001$ ) with a significant increase seen from 120 minutes.

EMG results were inconclusive. Over time, a decrease in the erector spinae co-contraction index was recorded $\left(\mathrm{F}_{6,66}=4.66, \mathrm{p}=0.026\right)$ in the static task, with the post hoc revealing the significant decrease occurred at 150 minutes. 
Table 3: Change in pressure variables over time for the dynamic task. Arrows indicate change from start, or previous increase. (30) Indicates the increase was from time 30, not time 0 . To calculate the average maximum change, each individual change over time was taken (both shoes) and the overall average calculated.

\begin{tabular}{|c|c|c|c|c|c|c|c|c|c|c|c|c|c|c|}
\hline \multirow{3}{*}{ Task } & \multirow{3}{*}{ Variable } & \multirow{3}{*}{ Region } & \multicolumn{6}{|c|}{ Time (minutes) } & \multirow{3}{*}{$\begin{array}{c}\mathrm{F} \\
\text { value }\end{array}$} & \multirow{3}{*}{$P$ value } & \multirow{2}{*}{\multicolumn{2}{|c|}{$\begin{array}{c}\text { Average } \\
\text { maximum } \\
\text { change from } \\
\text { start }\end{array}$}} & \multirow{2}{*}{\multicolumn{2}{|c|}{$\begin{array}{c}\text { Average } \\
\text { maximum \% } \\
\text { change from } \\
\text { start }\end{array}$}} \\
\hline & & & \multirow[t]{2}{*}{30} & \multirow[t]{2}{*}{60} & \multirow[t]{2}{*}{90} & \multirow[t]{2}{*}{120} & \multirow[t]{2}{*}{150} & \multirow[t]{2}{*}{180} & & & & & & \\
\hline & & & & & & & & & & & Mean & SD & Mean & SD \\
\hline \multirow{18}{*}{$\begin{array}{c}\text { Dynamic } \\
\text { Task }\end{array}$} & \multirow{5}{*}{$\begin{array}{c}\text { Mean Pressure } \\
(\mathbf{k P a})\end{array}$} & Foot & & $\uparrow$ & $\uparrow$ & & & $\uparrow$ & 18.89 & $<0.001$ & 3.36 & 1.80 & 22.23 & 15.59 \\
\hline & & Heel & $\uparrow$ & $\uparrow$ & & & & & 10.97 & $<0.001$ & 11.09 & 6.01 & 53.06 & 44.55 \\
\hline & & Lat mid & & & $\uparrow$ & & & & 4.65 & 0.005 & 3.57 & 3.68 & 40.47 & 64.82 \\
\hline & & Med mid & & $\uparrow(\mathbf{3 0})$ & & & & $\uparrow$ & 5.01 & 0.007 & 2.90 & 2.35 & 78.36 & 103.4 \\
\hline & & Mtpj4-5 & $\downarrow$ & $\uparrow$ & & & & & 5.68 & 0.001 & 4.58 & 5.06 & 44.35 & 50.07 \\
\hline & $\begin{array}{c}\text { Peak Pressure } \\
(\mathrm{kPa})\end{array}$ & Med mid & & $\uparrow$ & $\uparrow$ & & & $\downarrow$ & 4.30 & 0.008 & 8.78 & 6.34 & 14.41 & 10.56 \\
\hline & \multirow{8}{*}{$\begin{array}{c}\text { Contact Area } \\
(\%)\end{array}$} & Foot & & $\uparrow$ & & & $\uparrow$ & & 15.54 & $<0.001$ & 9.37 & 6.83 & 23.63 & 19.29 \\
\hline & & Heel & $\uparrow$ & & & $\uparrow$ & & & 10.84 & $<0.001$ & 14.67 & 7.44 & 30.79 & 25.04 \\
\hline & & Lat mid & & $\uparrow$ & & & $\uparrow$ & $\uparrow$ & 8.48 & $<0.001$ & 10.26 & 14.75 & 35.22 & 55.39 \\
\hline & & Med mid & & & & & $\uparrow$ & & 7.27 & 0.001 & 8.53 & 8.42 & 71.94 & 104.2 \\
\hline & & Mtpj1 & & $\uparrow(\mathbf{3 0})$ & & & $\uparrow$ & & 3.67 & 0.025 & 12.00 & 10.50 & 33.42 & 38.77 \\
\hline & & Mtpj2-3 & & $\uparrow(\mathbf{3 0})$ & & & $\uparrow$ & & 4.54 & 0.035 & 13.14 & 11.76 & 36.79 & 36.69 \\
\hline & & Mtpj4-5 & & & $\uparrow$ & & $\uparrow$ & & 10.60 & $<0.001$ & 14.98 & 14.10 & 44.71 & 43.00 \\
\hline & & Toes & $\downarrow$ & $\uparrow$ & & $\uparrow$ & & & 3.25 & 0.043 & 5.99 & 7.86 & 40.90 & 60.67 \\
\hline & \multirow{4}{*}{$\begin{array}{c}\text { PTI } \\
(\mathbf{k P a} s)\end{array}$} & Heel & $\uparrow$ & $\uparrow$ & & & & & 9.86 & $<0.001$ & 687.26 & 393.7 & 55.40 & 45.52 \\
\hline & & Lat mid & & & $\uparrow$ & & & & 5.24 & 0.010 & 264.61 & 240.7 & 54.18 & 82.80 \\
\hline & & Med mid & & & & $\uparrow$ & & & 4.30 & 0.025 & 177.30 & 130.6 & 108.0 & 272.9 \\
\hline & & Mtpj4-5 & $\downarrow$ & $\uparrow$ & & & & & 6.99 & $<0.001$ & 298.8 & 286.9 & 46.82 & 48.45 \\
\hline \multirow{8}{*}{$\begin{array}{l}\text { Static } \\
\text { Task }\end{array}$} & \multirow{2}{*}{$\begin{array}{c}\text { Mean pressure } \\
\text { (kPa) }\end{array}$} & Foot & & $\uparrow$ & & & & & 3.315 & 0.034 & 3.60 & 2.22 & 25.71 & 19.81 \\
\hline & & Heel & & $\uparrow$ & $\uparrow$ & & & & 6.93 & 0.001 & 18.27 & 6.80 & 18.27 & 6.80 \\
\hline & \multirow{2}{*}{$\begin{array}{c}\text { Peak Pressure } \\
(\mathbf{k P a})\end{array}$} & Foot & $\uparrow$ & & $\uparrow$ & & & & 5.47 & 0.001 & 40.26 & 25.38 & 40.20 & 28.33 \\
\hline & & Heel & $\uparrow$ & & $\uparrow$ & & & & 7.45 & $<0.001$ & 44.86 & 28.23 & 54.28 & 37.71 \\
\hline & \multirow{2}{*}{$\begin{array}{c}\text { Contact area } \\
(\%)\end{array}$} & Foot & & & & & & $\uparrow$ & 2.70 & 0.040 & 17.16 & 19.50 & 13.31 & 16.44 \\
\hline & & Heel & & $\uparrow$ & & & $\uparrow$ & & 3.86 & 0.024 & 37.11 & 72.76 & 34.56 & 60.41 \\
\hline & \multirow{2}{*}{ PTI (kPa s) } & Foot & & & $\uparrow$ & & & & 9.49 & $<0.001$ & 198.84 & 173.1 & 23.60 & 23.03 \\
\hline & & Heel & & & $\uparrow$ & & & & 12.39 & $<0.001$ & 775.26 & 630.9 & 87.26 & 157.2 \\
\hline
\end{tabular}




\section{The effect of footwear}

There was no statistical difference in the subjective VAS based sole hardness ratings between footwear $(p>0.05)$. The only subjective factor that differed was change in low back discomfort $\left(F_{1,11}=5.01, p=0.047\right)$, which was greater for the harder shoe (Figure 3, average values: $15.6 \pm 14.8 \mathrm{~mm}$, vs. $8.6 \pm 8.6 \mathrm{~mm}$ ). By the end of the 3 hours, the average discomfort in the harder shoe was $44 \%$ greater (mean increase softer=15.5 mm; mean increase harder shoe $=22.4 \mathrm{~mm}$ ).

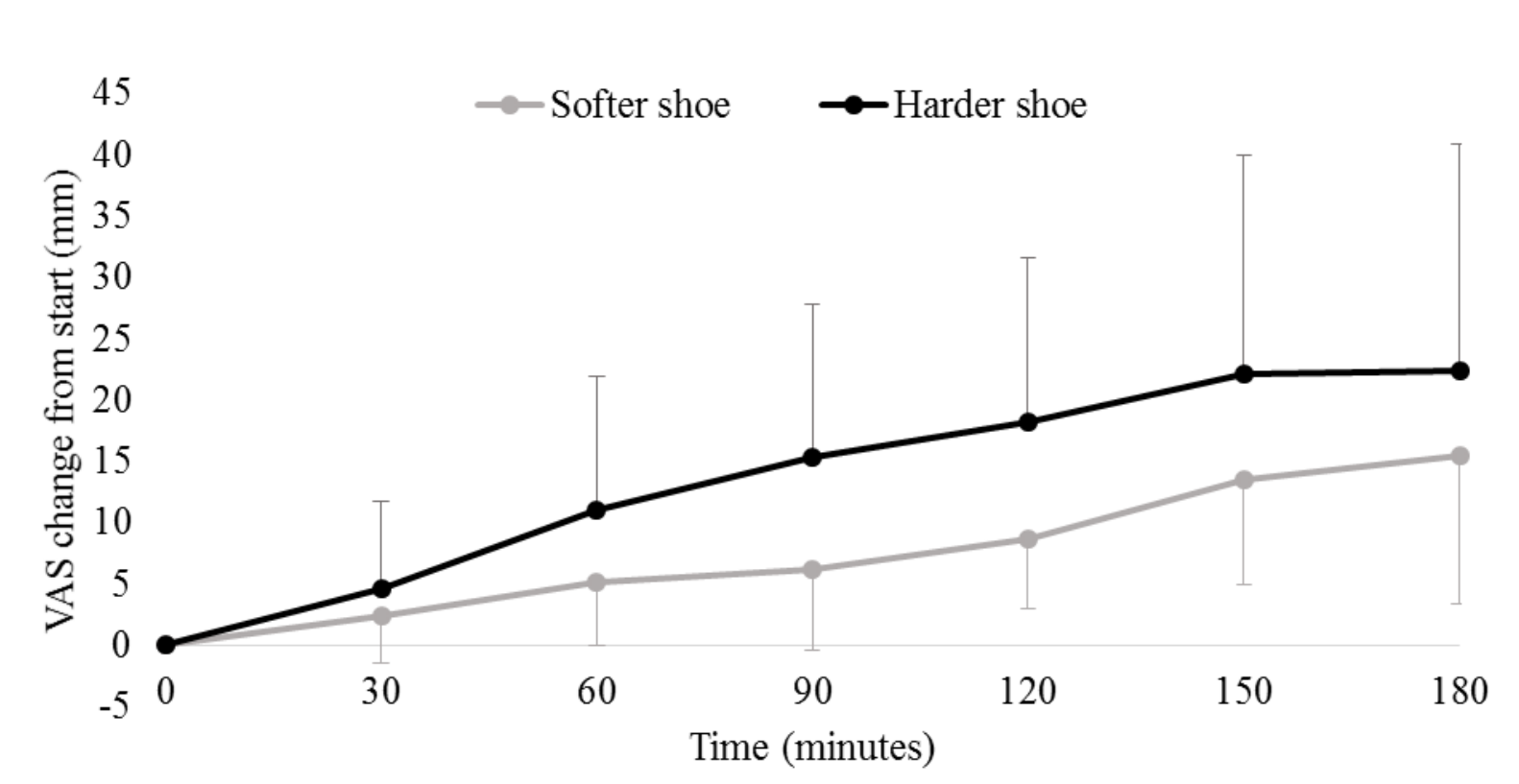

Figure 3. Change in low back discomfort from start for both shoes. Means and standard deviations are shown.

\section{Dynamic task}

Plantar pressure differences between footwear were observed (Table 4). The average overall change in mean heel pressure and PTI were greater in the softer shoe. Similarly, changes of PTI in the whole foot and lateral midfoot were greater in the softer shoe. The absolute contact area in the MTPJ23 region was greater in the softer shoe but the absolute PTI for the hallux region was lower in the softer shoe. Change in heel PTI demonstrated a significant interaction with shoe type $\left(\mathrm{F}_{6,66}=3.11, \mathrm{p}=0.040\right)$, with the softer shoe increasing at a greater rate.

Changes in hip adduction angle over time displayed a significant difference between footwear $\left(\mathrm{F}_{6,66}=9.01, \mathrm{p}=0.012\right)$ and a significant interaction $\left(\mathrm{F}_{6,66}=2.64, \mathrm{p}=0.042\right)$. The softer shoe was associated with an increase in hip adduction $\left(0.38 \pm 1.57^{\circ}\right)$ whereas the harder shoe reduced hip adduction over time $\left(-0.68 \pm 1.31^{\circ}\right)$. No further changes in EMG, COP, joint moments or angles were observed. 
Table 4. Differences between footwear for absolute variables and change over time, * indicates interaction effect between shoes over time.

\begin{tabular}{|c|c|c|c|c|c|c|c|c|c|c|}
\hline \multirow[t]{2}{*}{ Task } & \multirow[t]{2}{*}{ Measure } & \multirow[t]{2}{*}{ Variable } & \multirow[t]{2}{*}{ Region } & \multicolumn{2}{|c|}{$\begin{array}{c}\text { Mean softer } \\
\text { shoe }\end{array}$} & \multicolumn{2}{|c|}{$\begin{array}{c}\text { Mean harder } \\
\text { shoe }\end{array}$} & \multirow{2}{*}{$\begin{array}{c}\mathbf{F} \\
\text { value }\end{array}$} & \multirow{2}{*}{$\begin{array}{c}P \\
\text { value }\end{array}$} & \\
\hline & & & & Mean & SD & Mean & SD & & & \\
\hline \multirow{6}{*}{ Dynamic } & \multirow{4}{*}{$\begin{array}{l}\text { Change } \\
\text { over time }\end{array}$} & Mean pressure (kPa) & Heel & 7.91 & 5.97 & 3.47 & 4.22 & 7.56 & 0.019 & \\
\hline & & \multirow{3}{*}{ PTI (kPa s) } & Foot & 168.92 & 221.18 & 68.85 & 90.82 & 5.05 & 0.046 & \\
\hline & & & Heel & 589.4 & 473.0 & 208.7 & 253.5 & 15.92 & 0.002 & $*$ \\
\hline & & & Lateral midfoot & 167.4 & 307.2 & -18.1 & 186.4 & 6.93 & 0.023 & \\
\hline & \multirow{2}{*}{ Absolute } & Contact area $(\%)$ & MTPJ2-3 & 47.68 & 14.43 & 41.48 & 16.26 & 5.81 & 0.035 & \\
\hline & & PTI & Hallux & 1084.3 & 582.8 & 1314.2 & 576.2 & 6.74 & 0.046 & \\
\hline \multirow{8}{*}{ Static } & \multirow{6}{*}{$\begin{array}{l}\text { Change } \\
\text { over time }\end{array}$} & \multirow{2}{*}{ Mean pressure (kPa) } & Foot & 3.18 & 4.47 & 0.45 & 1.35 & 12.01 & 0.005 & \\
\hline & & & Lateral midfoot & 0.76 & 4.93 & -1.03 & 4.30 & 5.40 & 0.04 & \\
\hline & & \multirow{2}{*}{ Peak Pressure (kPa) } & Foot & 33.09 & 38.43 & 9.06 & 25.47 & 6.66 & 0.026 & \\
\hline & & & MTPJ4-5 & 7.69 & 19.90 & 0.08 & 18.66 & 5.45 & 0.04 & \\
\hline & & Contact area $(\%)$ & Foot & 4.92 & 11.62 & -0.29 & 5.01 & 7.59 & 0.019 & \\
\hline & & PTI & Foot & 113.64 & 155.35 & 32.64 & 89.03 & 5.49 & 0.039 & $*$ \\
\hline & \multirow{2}{*}{ Absolute } & \multirow{2}{*}{ Peak Pressure (kPa) } & Medial midfoot & 55.64 & 13.18 & 48.02 & 18.59 & 6.26 & 0.029 & \\
\hline & & & Hallux & 62.57 & 31.58 & 75.32 & 36.93 & 14.01 & 0.003 & \\
\hline
\end{tabular}

Static task

In the softer shoe, significantly greater average changes were seen for whole foot mean pressure, peak pressure and contact area. There was a significant interaction for change in foot PTI between shoes $\left(\mathrm{F}_{6,66}=4.073, \mathrm{p}=0.011\right)$ with a greater rate of increase in the softer shoe. Change in mean pressure in the lateral midfoot was greater in the softer shoe, as well as the change in peak pressure in the MTPJ4-5 region. Absolute peak pressure in the medial midfoot was greater in the softer shoe, but the absolute hallux peak pressure was lower.

Absolute stance width was statistically greater in the softer shoe for the static task $\left(\mathrm{F}_{1,11}=5.20\right.$, $\mathrm{p}=0.044$, mean softer shoe: $28.6 \pm 4.0 \mathrm{~cm}$, mean harder shoe: $27.1 \pm 5.2 \mathrm{~cm}$ ). No differences in joint angles, moments, COP or EMG were recorded.

\section{Footwear preference}

When asked which shoe was preferred, 8 participants identified a shoe ( 3 the harder shoe, 5 the softer shoe). The significant distinguishing factor between preferred and less preferred shoe were the following plantar pressure variables (Table 5).

In the preferred shoe, the absolute medial midfoot contact area was significantly greater in both tasks (static: $\mathrm{F}_{1,7}=7.44, \mathrm{p}=0.029$; preferred=35.7 $\pm 19.2 \%$ midfoot region, less preferred $=27.9 \pm 19.12 \%$ 
midfoot region; dynamic: $\mathrm{F}_{1,7}=15.36, \mathrm{p}=0.006$; preferred $=34.2 \pm 17.0 \%$ midfoot region, less preferred $=25.0 \pm 14.8 \%$ midfoot region). Individual results, bar one of the 8 participants, displayed a difference of $20 \%$ or more (Figure 4). Absolute medial midfoot PTI in both the static and dynamic tasks followed the same pattern. In the dynamic task, reductions in the lateral midfoot variables were also recorded.

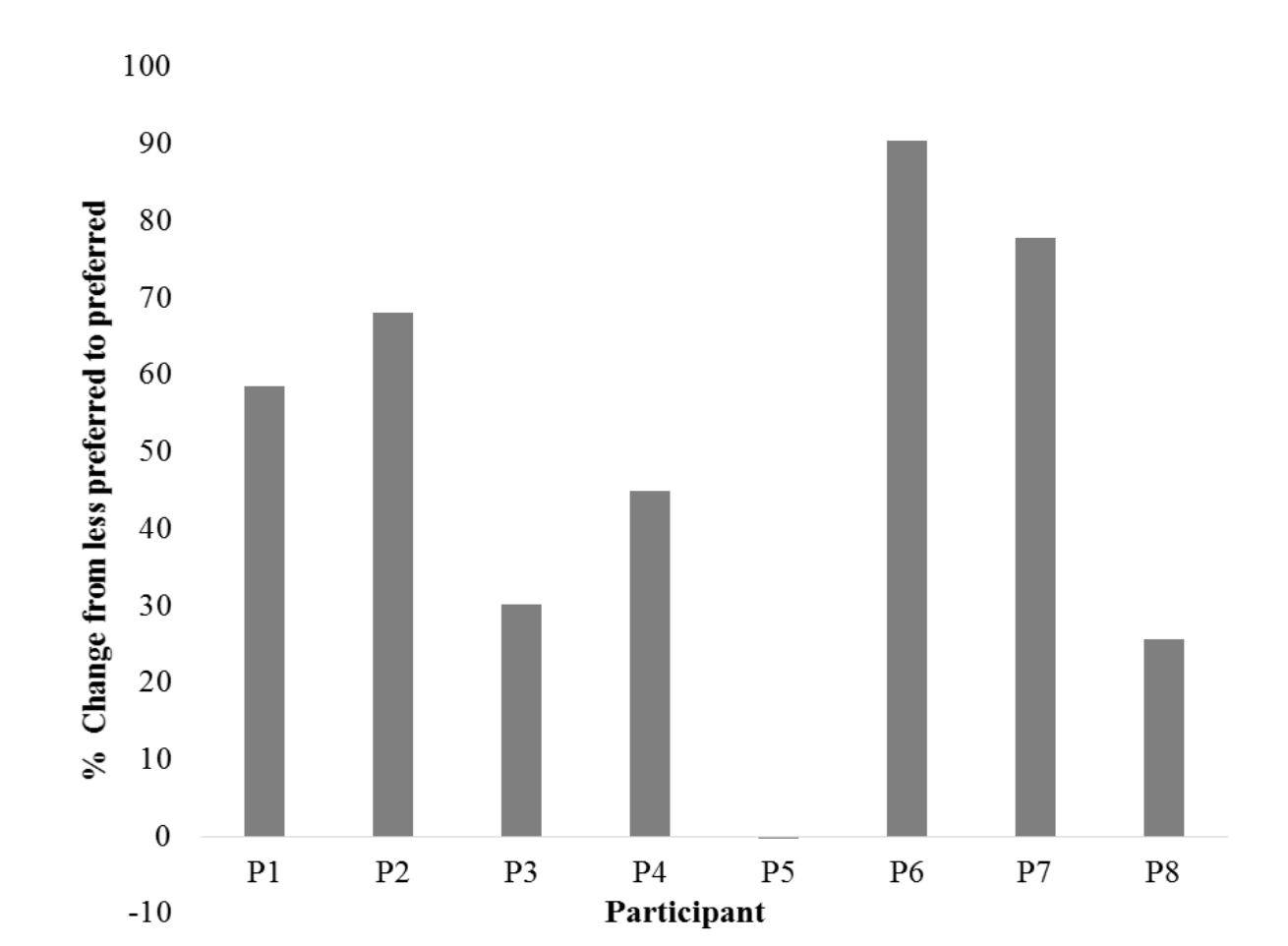

Figure 4. Difference in medial midfoot contact area for preferred and non-preferred footwear. Each bar represents the \% change from less-preferred footwear to preferred. Only one participant (P5) did not display a positive increase.

In the static task, a significant reduction in absolute mean heel pressure (17\%) and heel PTI (18\%) were seen in the preferred shoe (Table 5). Peak pressure values in the whole foot were significantly lower in the preferred shoe. Internal ankle inversion moment was significantly increased in the preferred shoe.

When considering the difference between participants that preferred the harder shoe $(n=3)$ versus those that preferred the softer shoe $(n=5)$, independent $t$-tests revealed that those that preferred the harder shoe were significantly taller (mean harder shoe: $1.74 \pm 0.01$, mean preferred softer shoe: $1.67 \pm 0.03, \mathrm{p}=0.010)$. 
Table 5. Difference between mean absolute variables for the preferred and less preferred shoe

\begin{tabular}{|c|c|c|c|c|c|}
\hline \multirow{2}{*}{ Task } & Variable & $\begin{array}{c}\text { Less } \\
\text { Shoe }\end{array}$ & $\begin{array}{c}\text { Preferred } \\
\text { Shoe }\end{array}$ & F value & P value \\
\hline Dynamic & Lateral midfoot mean pressure $(\mathrm{kPa})$ & 15.98 & 12.25 & 11.27 & 0.012 \\
\hline & Medial midfoot mean pressure (kPa) & 11.33 & 7.96 & 8.03 & 0.025 \\
\hline & Lateral midfoot contact area (\%) & 50.59 & 44.71 & 8.33 & 0.023 \\
\hline & Medial midfoot contact area (\%) & 34.18 & 24.97 & 15.36 & 0.006 \\
\hline & Lateral midfoot PTI (kPa s) & 956.13 & 804.88 & 9.03 & 0.020 \\
\hline \multirow{2}{*}{ Static } & Medial midfoot PTI (kPa s) & 688.96 & 485.71 & 8.07 & 0.025 \\
\hline & Medial midfoot contact area (\%) & 35.7 & 27.9 & 7.44 & 0.029 \\
\hline & Medial midfoot PTI (kPa s) & 669.8 & 495.3 & 11.06 & 0.013 \\
\hline & Mean Heel pressure (kPa) & 32.9 & 38.4 & 5.64 & 0.049 \\
\hline & Heel PTI (kPa s) & 1977.5 & 2342.2 & 7.77 & 0.027 \\
\hline & Ankle inversion moment (Nm/kg) & 0.104 & 0.088 & 18.02 & 0.004 \\
\hline
\end{tabular}

\section{Discussion}

This paper adds to the under-researched area of footwear for prolonged standing using a long duration simulated work-like task and, as far as the authors are aware, is the first to include in-shoe plantar pressure. Increases in discomfort, calf circumference and plantar pressure were recorded over time with footwear hardness impacting lower back discomfort and plantar pressure. Individuals had different footwear preferences, with a greater medial midfoot contact area recorded in the preferred shoe.

The increases in discomfort reported in this study over time are consistent with previous prolonged standing studies (Aghazadeh et al., 2015; Antle \& Cote, 2013; Cham \& Redfern, 2001; Kim $\&$ Stuart-Buttle, 1994; Coenen et al., 2017). The decreased lower back discomfort in the softer footwear mirrors the effects of softer flooring (Cham \& Redfern, 2001; King, 2002; Lin et al., 2012; Orlando and King, 2004), suggesting that it could provide a similar benefit whilst being individual and portable.

Calf circumference, a measure of blood pooling, is a contributing factor to lower limb and foot discomfort (Antle et al., 2013; Cham \& Redfern, 2001; Zander et al., 2004; Coenen et al., 2017), and increased throughout the 3 hours of standing. Blood pooling is thought to occur as standing increases venous hydrostatic pressure and reduces the venous muscle pump action (Coenen et al., 2017; Tüchsen 
et al., 2005). This causes a build up of fatigue and pain inducing metabolites and is thought to place stress on passive structures that could result in the associated symptoms (Edwards, 1988; Coenen et al., 2017). The theory that a softer surface promotes limb movement by increasing postural instability resulting in a reduction in blood pooling, has not been previously substantiated (Antle \& Cote, 2013; Cham \& Redfern, 2001; Zander et al., 2004). Similarly this study does not support the use of softer footwear to reduce lower limb blood pooling.

No evidence was found of either muscular fatigue over time or differences in muscular fatigue or back muscle co-contraction between footwear, which is reflective of similar previous literature (Antle et al., 2013; Coenen et al., 2017; Gregory \& Callaghan, 2008). Evidence of fatigue over time in the calf muscles during prolonged standing has been shown using muscle twitch force (Brownie \& Martin, 2015; Garcia et al., 2015), although these changes were recorded over 5 hours and did not differ between floor surfaces. Footwear type has previously been shown to determine if muscular fatigue occurs, with increased instability and thus more dynamic standing thought to be protective (Karimi et al., 2016). Therefore, it is possible that either the footwear in this study did not induce measurable levels of fatigue or that the tasks used were more dynamic and thus minimised fatigue. It has also been suggested that the low muscle contractions associated with prolonged standing are not ideal for recording spectral shifts (Cham \& Redfern, 2001), possibly a result of the shifts being insensitive to low muscle contractions. The lack of difference between footwear for erector spinae co-contraction has been previously recorded between different flooring, despite increases in low back discomfort (Aghazadeh, et al., 2015). Muscle co-activation during standing can vary between individuals (Nelson-Wong \& Callaghan, 2010), and it is feasible that fatigue in individual muscles could also be dependent on participant specific standing posture or pre-existing muscle preferences. Future research with a larger sample size should consider not only differences between conditions, but also consider differences between individuals.

Changes in plantar pressures over time resulted in altered ankle kinetics. Large pressures in the heel most likely cause the material to compress leading to an increased heel contact area (as the heel lowers into the compressed heel material), which is consistent with the increasing ankle dorsiflexion angle. In the dynamic task, this was followed by increases in lateral and medial midfoot pressures. The greater changes on the lateral compared to the medial midfoot likely occur as a result of the greater pressures at that site, which also explains the lateral shift in the centre of pressure. A corresponding increase in the internal inversion moment appears to prevent a change in the frontal plane foot angles. It is worth considering that changes in plantar pressure could also be influenced by changes in foot shape that could occur over time as a result of the blood pooling, as well as by alterations in the kinematics, such as the increase in knee flexion. Furthermore, the overall increase in plantar pressure seen most likely reflects material changes as a result of the prolonged compression, which is reinforced by the fact that these changes were greater in the softer shoe. Whilst plantar pressure increased over 
time, previous research has also shown that the foot becomes more sensitive to pressure over periods of prolonged standing (Messing \& Kilbom, 2001). Comfort therefore could be affected at a greater rate than pressure increases and be dependent on how time and pressure interact.

A softer shoe does not necessarily result in decreased pressures over a prolonged period. Although initially pressures are lower in softer soles/flooring, the greater changes in pressures over time in this study resulted in no overall difference in absolute pressure values after 180 minutes. As pressure and discomfort are related (Wiggerman \& Keyserling, 2015), this lack of difference in absolute pressure could perhaps explain why we see no difference in foot discomfort between the footwear. Standing applies a constant load to the footwear material, with very little or no time for the material to decompress or recover and no impact force. This contrasts with walking where the swing phase of gait removes load on the shoe sole for approximately $40 \%$ of the time (Holden, Chou \& Stanhope, 1997) and there is an impact at each step. Therefore, the need for cushioning may be decreased if a shoe was designed solely for standing. In terms of limiting changes in plantar pressure, this study suggests that a harder shoe would be more appropriate.

Footwear preference was also identified as an important factor. Increases in midfoot pressure variables and a corresponding decrease in heel pressures were the only biomechanical factors differentiating the preferred shoe from the non-preferred shoe. A more comfortable shoe has previously been associated with a greater medial midfoot contact area (Chen, Nigg, \& De Koning, 1994; Jordan, Payton, \& Bartlett, 1996) resulting in improved pressure dispersal with shoe preference (Chiu \& Wang, 2007). In terms of individual factors, those that preferred the hard shoe over the soft shoe were significantly taller. This finding is reinforced by previously reported correlations between increased height and a preference for a harder surface (King, 2002; Orlando \& King, 2004; Zander et al., 2004). Due to the fact the height of the work table was not individualised, differences in posture could occur. Taller individuals may lean over the table more, perhaps causing the COP to shift anteriorly and therefore the need for a harder material to maintain a comfortable midfoot section. The idea that individuals have a preference for different footwear based on biomechanical factors and individual characteristics has been previously reported (Miller et al., 2010; Mündermann, Stefanyshyn, \& Nigg, 2001). However, our understanding of this remains very limited and thus warrants considerable future work with robust methodology.

Although percentage differences between the footwear were reasonable it is worth noting that at 34 and 38 shore A, the footwear are both at the soft end of the Shore A range previously recorded in commercial footwear $\left(34-100^{\circ}\right)(B a r t o n$, Bonanno, \& Menz, 2009). However, this small difference on the Shore A scale was enough to elicit biomechanical and subjective differences.

This study has a number of limitations. In terms of preference of footwear, this was only asked at the end of the second day and involved remembering the feeling from the day before and making a 
comparison. Assessing preference over a shorter period would be a better replication of how shoes are chosen in real life. Due to the length of testing time and burden on participants, the number of participants was relatively low at 12 . Also, these participants did not usually work in a standing posture, although it is unknown if this would impact the results. Future research should consider how the foot shape changes over time, as this could have impacted plantar pressures and continue to investigate how changes in biomechanical variables over time vary between individuals.

In conclusion, this study has evidenced that during a period of prolonged standing changes in subjective discomfort, blood pooling, plantar pressure joint kinetics and joint kinematics occur. Softer footwear reduced lower back discomfort whilst harder footwear reduced changes in plantar pressure over time. Footwear preference varied amongst individuals, with foot contact area seemingly important. Future research should continue to focus on optimising individual footwear parameters in relation to individual characteristics and biomechanical data.

Words: 4972

Funding: This work was supported by the Knowledge Transfer Partnership programme (KTP0009994) which was co-funded by Toffeln Limited, UK and Innovate, UK.

Disclosure statement: The authors declare that there are no conflicts of interest.

\section{References:}

Aghazadeh, J., Ghaderi, M., Azghani, M. R., Khalkhali, H. R., Allahyari, T., \& Mohebbi, I. (2015). Anti-fatigue mats, low back pain, and electromyography: An interventional study. Int J Occup Med Environ Health, 28(2), pp. 347-356.

Andersen, J.H., Haahr, J.P., \& Frost, P. (2007). Risk factors for more severe regional musculoskeletal symptoms. Arthritis \& Rheumatism 56(4), pp.1355-64.

Anderson, J.A., Williams, A.E., \& Nester, C.J. (2016). A narrative review of musculoskeletal problems of the lower extremity and back associated with the interface between occupational tasks, feet, footwear and flloring. Musculoskeletal Care, 15(4), pp,304-315.

Antle, D. M., \& Cote, J. N. (2012). Relationships between lower limb and trunk discomfort and vascular, muscular and kinetic outcomes during stationary standing work. Gait Posture, 37(4), pp. 615-619.

Antle, D. M., Vezina, N., Messing, K., \& Côté, J. N. (2013). Development of discomfort and indicators of vascular and musculoskeletal disorders during a prolonged standing work task. Occupational Ergonomics, 11, pp. 21-23.

Arndt, A. (2003). Correction for sensor creep in the evaluation of long-term plantar pressure data. Journal of biomechanics, 36(12), pp. 1813-1817. 
Barton, C. J., Bonanno, D., \& Menz, H. B. (2009). Development and evaluation of a tool for the assessment of footwear characteristics. Journal of Foot and Ankle Research, 2(1), p 10.

Bergan, J.J., Schmid-Schönbein, G.W., Smith, P.D.C., Nicolaides, A.N., Boisseau, M.R., \& Eklof, B. (2006). Chronic Venous Disease. England Journal of Medicine, 355(5), pp.488-498.

Brownie, J., \& Martin, B. J. (2015). Muscle fatigue and discomfort associated wist standing and walking - comparison of work surfaces. Proceedings 19th Triennial Congress of the IEA, Melbourne 914 August 2015

Cham, R., \& Redfern, M. S. (2001). Effect of flooring on standing comfort and fatigue. Human Factors, 43(3), pp. 381-391.

Chen, H., Nigg, B., \& De Koning, J. (1994). Relationship between plantar pressure distribution under the foot and insole comfort. Clinical Biomechanics, 9(6), pp. 335-341.

Chiu, M. C., \& Wang, M. J. (2007). Professional footwear evaluation for clinical nurses. Appl Ergon, 38(2), pp. 133-141.

Coenen, P., Parry, S., Willenberg, L., Shi, J. W., Romero, L., Blackwood, D. M., ... Straker, L. M. (2017). Associations of prolonged standing with musculoskeletal symptoms-A systematic review of laboratory studies. Gait \& Posture, 58, pp. 310-318.

Cook, J., Branch, T., Baranowski, T., \& Hutton, W. (1993). The effect of surgical floor mats in prolonged standing: an EMG study of the lumbar paraspinal and anterior tibialis muscles. Journal of biomedical engineering, 15(3), pp. 247-250.

Edwards, R. H. (1988). Hypotheses of peripheral and central mechanisms underlying occupational muscle pain and injury. European journal of applied physiology and occupational physiology, 57(3), pp. 275-281.

Garcia, M. G., Laubli, T., \& Martin, B. J. (2015). Long-Term Muscle Fatigue After Standing Work. Hum Factors, 57(7), pp. 1162-1173. doi:10.1177/0018720815590293

Goonetilleke, R. S. (1999). Footwear Cushioning: Relating Objective and Subjective Measurements. Human Factors, pp. 241-256.

Gregory, D. E., \& Callaghan, J. P. (2008). Prolonged standing as a precursor for the development of low back discomfort: an investigation of possible mechanisms. Gait Posture, 28(1), pp. 86-92.

Halim, I., \& Omar, A.R. (2011). A review on health effects associated with prolonged standing in the industrial workplaces. International Journal of Recent Research and Applied Studies, 8(1), pp.14-21.

Hansen, L., Winkel, J., \& Jorgensen, K. (1998). Significance of mat and shoe softness during prolonged work in upright position: based on measurements of low back muscle EMG, foot volume changes, discomfort and ground force reactions. Applied Ergonomics, 29(3)

Holden, J.P., Chou, G., \& Stanhope, S.J. (1997). Changes in knee joint function over a wide range of walking speeds. Clinical Biomechanics, 12(6), p.375-382.

Jordan, C., Payton, C. J., \& Bartlett, R. M. (1996). Perceived comfort and pressure distribution in casual footwear. Fifth EMED User Meeting, 1996. 
Karimi, Z., Allahyari, T., Azghani, M.R., \& Khalkhali, H. (2016). Influence of unstable footwear on lower leg muscle activity, volume change and subjective discomfort during prolonged standing. Applied Ergonomics, 53, pp. 95-102.

Kim, J. Y., \& Stuart-Buttle, C. (1994). The effect of mats on back and leg fatigue. Applied Ergonomics, 25(1), pp. 29-34.

King, P. M. (2002). A comparison of the effects of floor mats and shoe in-soles on standing fatigue. Applied Ergonomics, 33, pp. 477-484.

Lin, Y. H., Chen, C. Y., \& Cho, M. H. (2012). Influence of shoe/floor conditions on lower leg circumference and subjective discomfort during prolonged standing. Appl Ergon, 43(5), pp. 965-970.

Madelaine, P., Voigt, M., \& Arendt-Nielsen, L. (1998). Subjective, physiological and biomechanical responses to prolonged manual work performed standing on hard and soft surfaces. European Journal of Applied Physiology, 77, pp. 1-9.

Meijsen, P., \& Knibbe, H.J.J. (2007). Prolonged standing in the OR: a Dutch research study. AORN journal, 86(3), pp.399-414.

Messing, K., \& Kilbom, A. (2001). Standing and very slow walking: foot pain-pressure threshold, subjective pain experience and work activity. Applied Ergonomics, 32, pp. 81-90.

Miller, J.E., Nigg, B.M., Liu, W., Stefanyshyn, D., \& Nurse, M.A. (2000). Influence of foot, leg and shoe characteristics on subjective comfort. Foot \& Ankle International, 21, pp. 759-767.

Műndermann, A., Stefanyshyn, D.J., \& Nigg B.M. (2001). Relationship between footwear comfort of shoe inserts and anthropometric and sensory factors. Medicine and Science in Sports and Exercise, 33(11), pp.1939-45.

Nelson-Wong, E., \& Callaghan, J. P. (2010). Is muscle co-activation a predisposing factor for low back pain development during standing? A multifactorial approach for early identification of at-risk individuals. Journal of Electromyography and Kinesiology, 20(2), pp. 256-263.

Nelson-Wong, E., Gregory, D.E., Winter, D.A., \& Callighan, J.P. (2008). Gluteus medius muscle activation patterns as a predicot of low back pain during standing. Clinical Biomechanics, 23, pp.545-553.

Nelson-Wong, E., Howarth, S.J., \& Callaghan, J. P. (2010). Acute biomechanical responses to a prolonged standing exposure in a simulated occupational setting. Ergonomics, 53(9), pp. 111728.

Orlando, A. R., \& King, P. M. (2004). Relationship of demographic variables on perception of fatigue and discomfort following prolonged standing under various flooring conditions. Journal of Occupational Rehabilitation, 14(1), pp. 63-76.

Price, C., Parker, D., \& Nester, C. (2016). Validity and repeatability of three in-shoe pressure measurement systems. Gait and Posture, 46, pp. 69-74. doi: 10.1016/j.gaitpost.2016.01.026

Sterud, T., \& Tynes, T. (2013). Work related psychosocial and mechanical risk factors for low back pain: a 3-year follow up study of the general working population in Norway. Occupational \& Environmental Medicine, 70, pp. 296-302. 
Sulsky, S.I., Carlton, L., Bochmann, F., Ellegast, R., Glitsch, U., Hartmann, B., ... Sun, Y. (2012). Epidemiological evidence for work load as a risk factor for osteoarthrits of the hip: a systematic review. PLoS ONE, 7(2), pp. e31521.

Tissot, F., Messing, K., \& Stock, S. (2009). Studying the relationship between low back pain and working postures among those who stand and those who sit most of the working day. Ergonomics, 52(11), pp. 1402-18.

Tüchsen, F., Hannerz, H., Burr, H., \& Krause, N. (2005). Prolonged standing at work and hospitalisation due to varicose veins: a 12 year prospective study of the Danish population. Occupational and Environmental Medicine, 62, pp. 847-850.

Waters, T. R., \& Dick, R. B. (2015). Evidence of health risks associated with prolonged standing at work and intervention effectiveness. Rehabilitation Nursing, 40(3), pp. 148-165.

Wiggermann, N., \& Keyserling, W. M. (2015). Time to onset of pain: Effects of magnitude and location for static pressures applied to the plantar foot. Applied Ergonomics, 46, pp. 84-90.

Zander, J. E., King, P. M., \& Ezenwa, B. N. (2004). Influence of flooring conditions on lower leg volume following prolonged standing. International Journal of Industrial Ergonomics, 34(4), pp. 279-288. 